Research Article

\title{
Forecasting Confirmed Cases, Deaths, and Recoveries from COVID-19 in China during the Early Stage
}

\author{
Lianyi Liu (D), Yan Chen (D), and Lifeng Wu \\ College of Management Engineering and Business, Hebei University of Engineering, Handan 056038, China \\ Correspondence should be addressed to Lifeng Wu; wlf6666@126.com
}

Received 23 May 2020; Accepted 7 July 2020; Published 29 July 2020

Academic Editor: Abdelalim A. Elsadany

Copyright (c) 2020 Lianyi Liu et al. This is an open access article distributed under the Creative Commons Attribution License, which permits unrestricted use, distribution, and reproduction in any medium, provided the original work is properly cited.

To provide a theoretical basis for the prevention and control of COVID-19 in China, confirmed cases, deaths, and recoveries from COVID-19 in China were predicted using a fractional grey model. The results indicated that the grey model has high forecasting accuracy in the prediction of disease spread.

\section{Introduction}

The outbreak of the novel coronavirus disease-2019 (COVID-19) caused by SARS-CoV-2 took place in December 2019 in Wuhan, China. This disease can cause severe fever and, in the worst cases, acute respiratory failure syndrome [1]. There were 1016 recorded deaths from this outbreak as of February 10, 2020, in China. It has also spread across other countries, starting with Japan and then Australia, France, and the United States. The SARS$\mathrm{CoV}-2$ virus continues to evolve in alarming ways, with the spread of COVID-19, putting enormous strain on health systems around the world. There is no indication that China will succeed in beating COVID-19 in the short term. Accurately forecasting the epidemic tendency can provide a theoretical basis for the prevention and control of COVID-19.

Statistical methods are widely used for forecasting of epidemic diseases [2]. Traditional prediction methods often require a large number of data samples, which follow a certain typical distribution. However, because of the limited information available during the early stages of disease transmission, the spreading mechanism of COVID-19 is yet to be fully understood [3]. The grey prediction theory provides a new way to solve the systemic problems that occur in cases of limited information. Thus, the grey prediction theory is more suitable for the prediction of the incidence of COVID-19 in China than other theories.

The rest of the paper is arranged as follows. Section 2 introduces the forecasting model. Section 3 shows in detail the prediction results. Conclusions are drawn in Section 4.

\section{Fractional Grey Model}

Grey system theory mainly focuses on systems with incomplete or uncertain information [4]. In recent years, grey system theory has been successfully applied to the prediction of infectious diseases [5-8].

Despite the widespread outbreak of COVID-19, data on this disease in China are limited. Many methods cannot make accurate predictions if the data samples are small. For this reason, the fractional grey model $(\operatorname{FGM}(1,1))$ is used to deal with the forecasting problem with limited samples [9]. The $\operatorname{FGM}(1,1)$ model is an optimized form of the grey prediction model. Its detailed modeling process has been described previously $[9,10]$.

\section{Results}

In this section, the data are from the National Health Commission of the People's Republic of China (http://www. nhc.gov.cn/). The Chinese government has made every effort 
TABle 1: Prediction of confirmed cases of COVID-19 in China.

\begin{tabular}{|c|c|c|c|}
\hline Data & Actual values & $\operatorname{FGM}(1,1)$ & MAPE \\
\hline 21-Jan & 291 & & \\
\hline 22-Jan & 440 & & \\
\hline 23-Jan & 571 & & \\
\hline 24-Jan & 1287 & & \\
\hline 25-Jan & 1975 & & \\
\hline 26-Jan & 2744 & 3207 & 16.89 \\
\hline 27-Jan & 4515 & 3961 & 12.27 \\
\hline 28-Jan & 5974 & 6462 & 8.17 \\
\hline 29-Jan & 7711 & 8362 & 8.44 \\
\hline 30-Jan & 9692 & 9881 & 1.95 \\
\hline 31-Jan & 11,791 & 12,037 & 2.08 \\
\hline $1-\mathrm{Feb}$ & 14,380 & 14,103 & 1.92 \\
\hline $2-\mathrm{Feb}$ & 17,205 & 17,271 & 0.38 \\
\hline 3-Feb & 20,438 & 20,418 & 0.10 \\
\hline 4-Feb & 24,324 & 23,973 & 1.44 \\
\hline $5-\mathrm{Feb}$ & 28,018 & 28,593 & 2.05 \\
\hline 6-Feb & 28,985 & 31,792 & 9.68 \\
\hline 7-Feb & 31,774 & 30,893 & 2.77 \\
\hline 8 -Feb & 33,738 & 33,145 & 1.76 \\
\hline 9-Feb & 35,982 & 35,965 & 0.05 \\
\hline Mean & & & 4.66 \\
\hline
\end{tabular}

Table 2: Prediction of the death toll due to COVID-19.

\begin{tabular}{|c|c|c|c|}
\hline Data & Actual values & $\operatorname{FGM}(1,1)$ & MAPE \\
\hline 22-Jan & 9 & & \\
\hline 23-Jan & 17 & & \\
\hline 24-Jan & 41 & & \\
\hline 25-Jan & 56 & & \\
\hline 26-Jan & 80 & & \\
\hline 27-Jan & 106 & 109 & 2.79 \\
\hline 28-Jan & 132 & 143 & 8.63 \\
\hline 29-Jan & 170 & 164 & 3.26 \\
\hline 30-Jan & 213 & 212 & 0.33 \\
\hline 31-Jan & 259 & 267 & 3.22 \\
\hline $1-\mathrm{Feb}$ & 304 & 311 & 2.22 \\
\hline $2-\mathrm{Feb}$ & 361 & 351 & 2.87 \\
\hline 3-Feb & 425 & 422 & 0.78 \\
\hline $4-\mathrm{Feb}$ & 490 & 500 & 2.02 \\
\hline $5-\mathrm{Feb}$ & 563 & 559 & 0.69 \\
\hline $6-\mathrm{Feb}$ & 636 & 643 & 1.16 \\
\hline 7-Feb & 722 & 714 & 1.13 \\
\hline 8 -Feb & 811 & 813 & 0.28 \\
\hline 9-Feb & 908 & 908 & 0.05 \\
\hline Mean & & & 2.10 \\
\hline
\end{tabular}

to fight the epidemic and has continued to release relevant data since January 21, 2020. Data released after January 21 were used to test the performance of the forecasts.

A rolling forecast approach was taken in the experiment. Here, the data of every five consecutive days were used as observations to predict the data for the next day. The mean absolute percentage error (MAPE) was used to test the performance of the model. The prediction results of the confirmed cases are presented in Table 1.

As shown in Table 1, the mean MAPE is $4.66 \%$, which meets our expectations for accurate forecasting. The $\operatorname{FGM}(1,1)$ model only needs five consecutive days of data to predict the next day's data. It needs very little data and follows the principle of new information priority. Even for the most uncontrollable first days of the epidemic, $\operatorname{FGM}(1,1)$ showed accurate prediction. Since February 28, the predicted MAPE has been less than 10\%, which demonstrates the adaptability of the model.

The number of deaths due to COVID-19 and the number of people who have recovered are shown in Tables 2 and 3, respectively.

As shown in Tables 2 and 3, the MAPE of the number of deaths and recoveries from COVID-19 was $2.10 \%$ and $3.61 \%$, respectively. All the MAPE values of the prediction results were less than $10 \%$, which means that the prediction results met the requirement of highly accurate prediction. 
TABle 3: Prediction of the number of people recovered from COVID-19.

\begin{tabular}{lcc}
\hline Data & Actual values & FGM(1,1) \\
\hline 24-Jan & 38 & \\
25-Jan & 49 & \\
26-Jan & 51 & \\
27-Jan & 60 & \\
28-Jan & 103 & \\
29-Jan & 124 & 129 \\
30-Jan & 171 & 169 \\
31-Jan & 243 & 225 \\
1-Feb & 328 & 318 \\
2-Feb & 475 & 441 \\
3-Feb & 632 & 646 \\
4-Feb & 892 & 843 \\
5-Feb & 1153 & 1217 \\
6-Feb & 1540 & 1536 \\
7-Feb & 2050 & 1975 \\
8-Feb & 2649 & 2669 \\
9-Feb & 3281 & 3381 \\
Mean & & \\
\hline
\end{tabular}

TABLE 4: The forecasting results of $\operatorname{FGM}(1,1)$.

\begin{tabular}{lcccc}
\hline Data & Number of confirmed cases & Growth rate of confirmed cases (\%) & Number of deaths & Number of recoveries \\
\hline $10-\mathrm{Feb}$ & 37,857 & 5.21 & 1011 & 4160 \\
$11-\mathrm{Feb}$ & 39,742 & 4.98 & 1123 & 5240 \\
$12-\mathrm{Feb}$ & 41,585 & 4.64 & 1244 & 6582 \\
$13-\mathrm{Feb}$ & 43,397 & 4.36 & 1373 & 8253 \\
$14-\mathrm{Feb}$ & 45,186 & 4.12 & 1513 & 10,333 \\
\hline
\end{tabular}

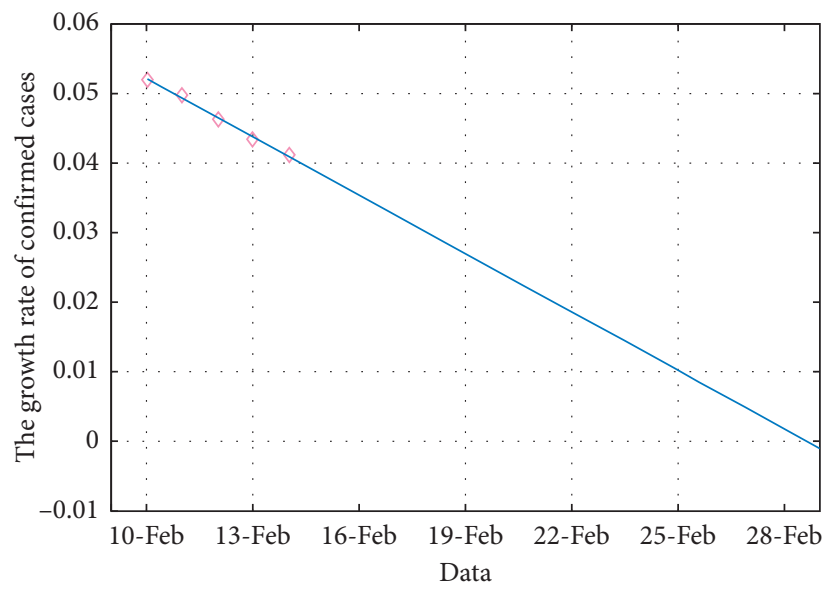

Figure 1: Prediction of the growth rate of the number of confirmed cases.

Therefore, we took the next step to predict the future number of confirmed, dead, and recovered cases, as shown in Table 4.

The predictions show that the growth rate of the number of confirmed cases was on the decline, and the number of recoveries was on the rise. Based on the above results, we further predicted the growth rate of confirmed cases. From the existing data, the growth rate showed a straight-line downward trend, so linear regression was used for prediction. The predictive effect is shown in Figure 1. We could draw the conclusion that the inflection point would be reached around February 29, the spread of COVID-19 would be effectively controlled, and the number of people infected would not increase much.

\section{Conclusions}

The spread of COVID-19 has caused great damage to the world's health care systems, so it is very necessary to predict the spread of disease in the future. In the early stages of the outbreak, data are limited and not absolutely accurate. The $\operatorname{FGM}(1,1)$ model is a good choice at the early stage of disease 
transmission for the prediction of trends of this new disease. $\operatorname{FGM}(1,1)$ is suitable for short-term prediction of time series. Using the characteristics of fractional-order accumulation, the grey model can analyze the rules in short-term data well based on the principle of new information first. Hence, $\operatorname{FGM}(1,1)$ could accurately predict the number of confirmed cases, the number of deaths, and the number of recoveries. The predicted results indicate that the spread of COVID-19 will be further suppressed in China, more people will be cured, and infection rates will fall further.

\section{Data Availability}

The data used to support the findings of this study are available from the corresponding author upon request.

\section{Conflicts of Interest}

The authors declare that there are no conflicts of interest regarding the publication of this paper.

\section{Acknowledgments}

This research was supported by the National Natural Science Foundation of China (71871084), the Scientist Foundation of Hebei Education Department (SQ201027 and ZD202007), and the Excellent Young Scientist Foundation of Hebei Education Department (SLRC2019001).

\section{References}

[1] WHO, WHO to Accelerate Research and Innovation for New Coronavirus, WHO, Geneva, Switzerland, 2020, https://www.who. int/news-room/detail/06-02-2020-who-to-accelerate-research-andinnovation-for-new-coronavirus.

[2] R. Xu, "Global dynamics of an SEIS epidemic model with saturation incidence and latent period," Applied Mathematics and Computation, vol. 218, no. 15, pp. 7927-7938, 2012.

[3] J. T. Wu, K. Leung, and G. M. Leung, "Nowcasting and forecasting the potential domestic and international spread of the 2019-nCoV outbreak originating in Wuhan, China: a modelling study," The Lancet, vol. 395, no. 10225, https://www. sciencedirect.com/science/article/pii/S0140673620302609, 2020.

[4] K. K. Emmanuel, "Forecasting the total energy consumption in Ghana using grey models," Grey Systems: Theory and Application, vol. 9, no. 4, pp. 488-501, 2019.

[5] X. Guo, S. Liu, and Y. Yang, "A prediction method for plasma concentration by using a nonlinear grey Bernoulli combined model based on a self-memory algorithm," Computers in Biology and Medicine, vol. 105, pp. 81-91, 2019.

[6] X. J. Shen, L. M. Ou, X. J. Chen et al., "The application of the grey disaster model to forecast epidemic peaks of typhoid and paratyphoid fever in China," PLoS One, vol. 8, Article ID e60601, 2013.

[7] L. Zhang, Y. Zheng, K. Wang et al., "An optimized Nash nonlinear grey Bernoulli model based on particle swarm optimization and its application in prediction for the incidence of Hepatitis B in Xinjiang, China," Computers in Biology and Medicine, vol. 33, no. 4, pp. 1073-1078, 2014.

[8] Y. Wang, Q. Du, F. Ren et al., "Spatio-temporal variation and prediction of Ischemic heart disease hospitalizations in Shenzhen, China," International Journal of Environmental
Research and Public Health, vol. 11, no. 5, pp. 4799-4824, 2014.

[9] L. Liang, S. Liu, L. Yao, and D. Liu, "Grey system model with the fractional order accumulation," Communications in Nonlinear Science and Numerical Simulation, vol. 18, no. 7, pp. 1775-1785, 2013.

[10] Y. Yan, W. Lifeng, L. Lianyi, and Z. Kai, "Fractional Hausdorff grey model and its properties," Chaos, Solitons \& Fractals, vol. 138, p. 109915, 2020. 